\title{
LESSONS LEARNED FROM TEACHING PROJECT-BASED SYSTEMS ANALYSIS AND DESIGN
}

\author{
Wenli Wang, Robert Morris University, wangw@rmu.edu
}

\begin{abstract}
Systems analysis and design is a required course in Information Systems programs. Students can benefit from a hands-on real-world project in a systems course. How to effectively teach a project-based systems course? This research studies the student data from 186 students in ten sessions of two systems courses over three years. And the data show that: 1) A group project assignment has a higher project completion rate and better project performance than those of an individual project assignment; 2) Groups with a group size of two have a higher project completion rate and better group project performance than those with a larger group size such as four; 3) Students in an advanced systems course consistently perform better than those in an introductory systems course for project assignments; 4) Undergraduate students in an evening class have better course performance than those in an afternoon class, given that the two classes are conducted in the same manner; and 5) Graduate students perform better than undergraduate students for the same course taught in the same manner. This paper also discusses the reasons for the above results as well as some nuances in effectively teaching project-based systems courses.
\end{abstract}

Keywords: IS Education, Systems Analysis and Design, CIS Curriculum, Project Approach, Group Size, Retention

\section{INTRODUCTION}

Systems analysis and design is generally a required course in Information Systems (IS) related degree programs such as Computer Information Systems (CIS) and Management Information Systems (MIS) programs. Since the understanding of systems is so important for IS students, undergraduate programs accredited by ABET typically require two courses - an introductory systems analysis and design (SAD) course and an advanced SAD course.

The content of systems courses is diverse. Students need to learn about both business- and technology-related principles as well as knowledge and cultivate relevant skillsets. It is recommended to have students practice the learned principles, knowledge, and skills through a hands-on real-world project in which students can integrate, consolidate, and apply what they have just learned. Project-based education is important for IS students because these students need to experience first-hand how to produce systems-one of the objectives of an academic IS program [1]. SAD and Advanced SAD courses are good candidate courses for having these first-hand experiences.

Introducing a hands-on real-world project in a systems course is not easy because a real-world project is typically more complex and on a larger scale than textbook case exercises. The author has experimented with such projects in the multiple sessions of SAD/Advanced SAD courses and intends to answer the following five research questions:

RQ1: Does a group project assignment have a higher project completion rate and better project performance than those of an individual project assignment, given that the group and individual project assignments are comparable in complexity and in scale?

RQ2: What size of a group has a higher group project completion rate and better group project performance? Is the group size the bigger, the better?

RQ3: Do students in an Advanced Systems Analysis and Design course perform better than those in an introductory Systems Analysis and Design course in a project assignment, given that the project assignments in these two courses are comparable in complexity and in scale?

RQ4: Do undergraduate students in an evening class have better course performance than those in a daytime class, given that the two classes are for the same course and are conducted the same way by the same instructor? 
RQ5: Do graduate students perform better than undergraduates for the same course taught in the same manner?

The paper is organized as follows: Section II introduces the basic course information and descriptive statistics of the multiple sessions of the SAD and Advanced SAD courses. Section III answers the questions and discusses the reasons for the answers. Nuances in effectively teaching systems courses are also discussed. Section IV concludes.

\section{COURSE INFORMATION AND DESCRIPTIVE STATISTICS}

During the six semesters between Fall 2012 and Spring 2015, the author has taught SAD four times and Advanced SAD six times in an ABET accredited CIS program at a private university. All of the courses are at the undergraduate level except for one graduate course in Fall 2014, which is called "Object-oriented" SAD and uses the same textbook as the undergraduate Advanced SAD course that has the same focus on the object-oriented approach. There is no prerequisite for OO-SAD graduate course; however, for undergraduates, the introductory SAD course is a prerequisite for the Advanced SAD. Students in introductory SAD are mostly sophomore and juniors in the CIS degree program, and students in Advanced SAD are mostly juniors and seniors in the CIS program.

The project can either be an individual project (i.e., group size=1) or a group project. Students formed groups by themselves after they shared their business/technical background with the class and were given the project's Request for Proposal (RFP) and the proposal template (see Appendix). The instructor typically does not intervene with the forming of the groups but does gently help build balanced, comparable groups with supplementary skills and cultural diversity and harmony. Students who intend to become project managers in future careers were encouraged to volunteer as group leaders and were held responsible throughout the course for group management. For groups without volunteered leaders (which rarely happened), the instructor appointed group leaders.

\section{Basic Information and Descriptive Statistics of the Introductory Systems Analysis and Design Course}

The course information and descriptive statistics from the four sessions of the introductory SAD course in three semesters are exhibited in Table 1 below. There was one online session and three on-ground sessions. All of them were fifteen-week semester-long sessions. Two of the three on-ground sessions were offered simultaneously in the same semester of Fall 2013, with one session in the afternoon and the other in the evening.

Table 1. Information and Descriptive Statistics from the Four Sessions of the SAD Course in Three Semesters

\begin{tabular}{|l|c|c|c|c|c|}
\hline \multicolumn{5}{|c|}{ Course: Systems Analysis and Design } \\
\hline Semester & Fall 2012 & Fall 2013_C1 & Fall 2013_C2 & Fall 2014 & Average \\
\hline Mode & online & on-ground & on-ground & on-ground & - \\
\hline Duration & 15 weeks & 15 weeks & 15 weeks & 15 weeks & 15 weeks \\
\hline Class Time & N/A & afternoon & evening & afternoon & - \\
\hline Level & undergraduate & undergraduate & undergraduate & undergraduate & undergrad \\
\hline \# of Students & 20 & 20 & 18 & 18 & 19 \\
\hline Group Size & 1 (individual) & 4 & 4 & 4 & 3.25 \\
\hline Project Topic & $\mathrm{A}$ & $\mathrm{A}$ & $100 \%$ & $100 \%$ & $96 \%$ \\
\hline $\begin{array}{l}\text { Project } \\
\text { Completion Rate }\end{array}$ & $85 \%$ & $100 \%$ & $100 \%$ & $94 \%$ & $98.5 \%$ \\
\hline $\begin{array}{l}\text { Course } \\
\text { Retention Rate }\end{array}$ & $100 \%$ & $100 \%$ & $85 \%$ & $87 \%$ & $81 \%$ \\
\hline $\begin{array}{l}\text { Average Project } \\
\text { Grade }\end{array}$ & $74 \%$ & $76 \%$ & $76 \%$ & $88 \%$ & $80 \%$ \\
\hline $\begin{array}{l}\text { Average } \\
\text { Midterm Grade }\end{array}$ & $87 \%$ & $70 \%$ & $92 \%$ & $87 \%$ \\
\hline $\begin{array}{l}\text { Average Final } \\
\text { Exam Grade }\end{array}$ & $87 \%$ & $82 \%$ & & 4 \\
\hline
\end{tabular}

*Project A: Website design for a non-profit contemplation-related organization and its subsidiaries [4] 
The same textbook "Systems Analysis and Design," ninth edition, by Shelly \& Rosenblatt [3] was used for all of the four sessions. The course content and the chapter assignments for these four sessions were mostly the same. The midterm and the final exams were mostly the same - all of them used multiple-choice questions and the numbers of the questions in the exams were comparable. The final exams were not accumulative and only covered the content after the midterm exams.

The same project assignment self-developed by the author-website design for a non-profit contemplation-related organization and its subsidiaries [4] — was used. Students were given mostly the same information of the project (a non-profit organization's Request for Proposal in a written form) and the same project template (see Appendix). The projects were graded in the same manner independently by the same instructor.

There were a total of seventy-six (76) students. The class sizes of these four sessions are comparable with an average class size of nineteen (19) students and a very small variance. The maximum class size was twenty (20) students and the minimum class size was eighteen (18) students.

\section{Basic Information and Descriptive Statistics of the Advanced Systems Analysis and Design Course}

The information and descriptive statistics from the six sessions of the Advanced SAD undergraduate/OO-SAD graduate courses in six semesters are exhibited in Table 2 below. There were three online sessions and three onground sessions. All of the online courses were eight weeks in length. All of the on-ground courses were fifteen weeks in length and were offered in the evenings. All six sessions were offered at the different semesters between Fall 2012 and Spring 2015.

Table 2. Information and Descriptive Statistics from the Six Sessions of the Advanced SAD Course in Six Semesters

\begin{tabular}{|l|c|c|c|c|c|c|c|}
\hline \multicolumn{7}{|c|}{$\begin{array}{c}\text { Courses: Advanced Systems Analysis and Design (Undergraduate) } \\
\text { or Object-oriented Systems Analysis and Design (Graduate) }\end{array}$} \\
\hline \multicolumn{1}{|c|}{ Semester } & $\begin{array}{c}\text { Spring } \\
\mathbf{2 0 1 3}\end{array}$ & $\begin{array}{c}\text { Spring } \\
\mathbf{2 0 1 4}\end{array}$ & $\begin{array}{c}\text { Spring } \\
\mathbf{2 0 1 5}\end{array}$ & Fall 2012 & Fall 2013 & Fall 2014 & Average \\
\hline Mode & on-ground & on-ground & on-ground & online & online & online & - \\
\hline Duration & 15 weeks & 15 weeks & 15 weeks & 8 weeks & 8 weeks & 8 weeks & - \\
\hline Class Time & evening & evening & evening & N/A & N/A & N/A & - \\
\hline Level & undergrad & undergrad & undergrad & undergrad & undergrad & graduate & - \\
\hline \# of Students & 28 & 26 & 14 & 4 & 21 & 17 & 18 \\
\hline Group Size & 4 & 4 & 2 & 1 (individual) & N/A & N/A & 2.75 \\
\hline Project Topic & A & B** & A & A & No project & No project & - \\
\hline $\begin{array}{l}\text { Project } \\
\text { Completion } \\
\text { Rate }\end{array}$ & $86 \%$ & $100 \%$ & $100 \%$ & $75 \%$ & N/A & N/A & $90 \%$ \\
\hline $\begin{array}{l}\text { Course } \\
\text { Retention Rate }\end{array}$ & $79 \%$ & $96 \%$ & $93 \%$ & $100 \%$ & $100 \%$ & $100 \%$ & $95 \%$ \\
\hline $\begin{array}{l}\text { Average } \\
\text { Project Grade }\end{array}$ & $82 \%$ & $91 \%$ & $90 \%$ & $85 \%$ & N/A & N/A & $87 \%$ \\
\hline $\begin{array}{l}\text { Average } \\
\text { Midterm } \\
\text { Grade }\end{array}$ & $73 \%$ & $77 \%$ & $83 \%$ & N/A & N/A & N/A & $78 \%$ \\
\hline $\begin{array}{l}\text { Average Final } \\
\text { Exam Grade }\end{array}$ & $51 \%$ & $69 \%$ & $95 \%$ & $73 \%$ & $73 \%$ & $80 \%$ & $74 \%$ \\
\hline
\end{tabular}

"Project A: Website design for a non-profit contemplation-related organization and its subsidiaries [4]

${ }^{* *}$ Project B: Website design for a non-profit healthcare-related organization and its subsidiaries [5] 
The same textbook "Systems Analysis and Design in a Changing World," sixth edition, by Satzinger, et al. [2] was used for all of the six sessions. The course content and the chapter assignments for these six sessions were mostly the same. The midterm and the final exams were mostly the same-all of them used multiple-choice questions and the numbers of the questions in the exams were comparable. If there was no midterm exam, then the final exam was equivalent to the total of the midterm and the final exam in other comparable sessions.

The same project assignment self-developed by the author-Project A: website design for a non-profit contemplation-related organization and its subsidiaries [4] — was assigned for three sessions (two on-ground as group project and one online as an individual project). A different project assignment also self-developed by the author-Project B: website design for a non-profit healthcare-related organization and its subsidiaries [5] —was assigned to one on-ground session as a group project. Project A in the Advanced SAD course is the same as the Project A in the introductory SAD course. For the three online sessions, only during the first session Project A was assigned as an individual project assignment. No project assignment was assigned in the latter two online sessions.

For Project A, students were given mostly the same project information (a non-profit organization's Request for Proposal in a written form) and the same project template (see Appendix). However, for Project B, different information was given due to the fact that the real-world non-profit organization was at the different development stage than that in Project A. There was no formal request for proposal in the written form, but more detailed functional descriptions and professional user interface designs were provided to the students as the project information and examples. The project template was identical as that in Project A. Although there were some gives and takes, these two projects were comparable in complexity and in scale. The projects were graded in the same manner independently by the same instructor.

There were a total of one hundred and ten (110) students. The average class size was eighteen (18) students (comparable to the average class size for the SAD course) with a relatively larger variance. The maximum class size was twenty eight (28) students and the minimum class size was four (4) students.

\section{ANSWERS AND DISCUSSIONS}

Based on the course information and the descriptive statistics of the multiple sessions of the SAD course and the Advanced SAD course, the five research questions are answered and discussed below:

RQ1: Does a group project assignment have to a higher project completion rate and better project performance than those of an individual project assignment, given that the group and individual project assignments are comparable in complexity and in scale?

Answer: A group project assignment has a higher project complete rate and better group performance than those of an individual project assignment, given that the group and individual project assignments are comparable in complexity and in scale.

Discussion: All group project assignments were completed and submitted in all the sessions of both SAD and Advanced SAD courses where group assignments were assigned except for one group where all group members withdrew from the course (Spring 2013, Advanced SAD). Including the group withdrawn, the project completion rate for a group project assignment was on average $97.7 \%$. In comparison, for an individual project assignment, the project completion rate was on average $80 \%$, lower than that of the group project assignment. Three out of twenty students in the Fall 2012 online SAD course and one out of four students in the Fall 2012 online Advanced SAD course did not submit/complete the individual project assignment. The average group project grade was $85.2 \%$ whereas the average individual project grade was $79 \%$. Table 3 below provides the summary data. The conclusion is that for introducing hands-on, real-world projects in systems courses, it is better to assign group project assignments than individual project assignments, especially for the undergraduate students. 
Table 3. A Group Project Assignment has a Higher Project Completion Rate and Better Project Performance than those of an Individual Project Assignment

\begin{tabular}{|l|c|c|}
\hline $\begin{array}{c}\text { Project Completion Rate } \\
\text { and Performance }\end{array}$ & Group Project Assignment & Individual Project Assignment \\
\hline Average Project Completion Rate & $97.7 \%$ & $80 \%$ \\
\hline Average Project Grade & $85.2 \%$ & $79 \%$ \\
\hline
\end{tabular}

Reaching high project completion rate is important because it relates to the course retention rate, and the course retention rate is a critical factor for ABET accreditation. For the Advanced SAD course in Spring 2013 where all of its four members in one group withdrew from the course, the project completion rate was the lowest of $86 \%$, whereas all other group projects in other semesters have completion rates of $100 \%$. Consequently, the course retention rate for that session was the lowest as well, which is only $79 \%$, whereas the average course retention rate for other courses with group project assignments is $96.6 \%$.

Typically, for those sessions without a full $100 \%$ retention rate, only one student withdrew from the course. Sometimes, students withdrew at the first half of the course; sometimes, students withdrew when the course finished about two-thirds of its content. In the case of Spring 2013 Advanced SAD course where the four group member withdrew, the group leader (who was the only female student in class and got the highest midterm exam grade) withdrew first when the course was at about two-thirds of its progress line. At that time, two other group members actually came to the office hour and tried to continue working on the project but did not tell the instructor that the group leader withdrew (or they did not even know). Soon after that, they felt that they could not do a good job and the group leader's departure made them less confident that they could accomplish what was expected. These two group members withdrew from the course when the course was at about three-fourths of its progress line. And then the cascading effect reached the last group member who later withdrew as well. A year later, the female student reregistered for the same course with the same instructor in Spring 2014, volunteered as a group leader again, and successfully led and completed the group project (Project B). She told the instructor that her reason for withdrawal from Spring 2013 was totally personal - she was simply too busy with her professional work at that time. She was not aware of the cascading effects on her group members after her withdrawal.

The lesson learned here is that the instructor needs to pay close attention to who withdraws from a course and when, especially for those who have leadership roles in a group project and when there is a potential cascading effects on other remaining group members. Students who contemplate on withdrawing typically do not discuss their intent to quit with the instructor or the fellow classmates. Often times, both the instructor and the remaining group members were left without any warning or notification unless the instructor keeps a frequent check on the roster. When the instructor knows about it, it could be too late. Otherwise, special arrangements could have been made to help and encourage the remaining group members. It would be helpful if the registrar's office pushes out event-triggered, timely changes of the course rosters to the instructors rather than having the instructors pull roster information at certain time intervals. Reaching high course retention rate should be an integrated team effort from both the faculty and the administrators.

RQ2: What size of a group has a higher project completion rate and better group project performance? Is the group size the bigger, the better?

Answer: The bigger group size does not imply the higher project completion rate or better group performance. A group with a group size of two members has a higher project completion rate and better group project performance than those of a group with a group size of four members.

Discussion: Group sizes of one (i.e., individual), two, and four were experimented at the different sessions of the same course (shown in Tables 1 and 2). The average group project completion rate was $100 \%$ for groups with a group size of two members whereas the group project completion rate was $97.2 \%$ for groups with a group size of four members. The average project grade for groups with a group size of two members was $90 \%$ whereas the average project grade for groups with a group size of four members was $84 \%$. Table 4 below shows the summary data. As mentioned above in the answer to RQ1, the average individual project completion rate was only $80 \%$ and the average individual project grade was only $79 \%$. 
Table 4. Groups with a Group Size of Two Members have a Higher Project Completion Rate and Better Project Performance than those of Groups with a Group Size of Four Members

\begin{tabular}{|l|c|c|}
\hline Project Completion Rate and Performance & Group Size of Two & Group Size of Four \\
\hline Average Project Completion Rate & $100 \%$ & $97.2 \%$ \\
\hline Average Project Grade & $90 \%$ & $84 \%$ \\
\hline
\end{tabular}

For a real-world hands-on project with complexity and a large scale, a group project assignment is easier for students to handle than an individual project assignment. For a group project assignment, when the group size gets larger, the group may be more difficult to lead or manage. There is also an increased overhead cost of coordination and potential free-riding. A group size of two (and maybe three) rather than four or more, is a middle-way approach where group members can still supplement each other's capacities and skills, each member is more accountable, and there is reasonably lower overhead cost of coordination. Typically, it is sufficient to have two members in a group with one group member having strength in business/systems and the other member having strength in technology/ programming. With a small group size, it is clear to everyone that no one in a group could possibly free-ride because it is simply unfair for one member to complete the entire group project. The responsibilities are clearly divided between the two members in a timely fashion-even the instructor knows early on in class which group member is in responsible for what content. Where there were four group members, the instructor was often told that the group would decide on individual's responsibilities later in some off-class meetings and later on the instructor was not informed clearly who was responsible for what content.

There was a similar incident of withdrawing from the course - one of the members in a group of two in Spring 2015 (also in an Advanced SAD course) withdrew from the course after about two-thirds of the semester without telling either the team member or the instructor. The remaining one group member immediately contacted the instructor and the instructor right away moved the student to another group. The student switched to another group was happy. There was no cascading effect or further withdrawals from the course. It is easier to manage a smaller group, both for students and for student-instructor interactions. There is simply more information transparency and less coordination cost among two or three students than those among four students. It is easier to coordinate meetings among two or three students than among four students. And instructors were notified earlier of any potential problems.

The average group performance for a small group size of two students turned out to be higher, which also implies that a much higher individual learning outcome because each student contributes to and is accountable for about half of the project rather than a fourth in case of a group size of four students.

RQ3: Do students in an Advanced Systems Analysis and Design course perform better than students in an introductory Systems Analysis and Design course in a project assignment, given the project assignments in these two courses are comparable in complexity and in scale?

Answer: Students in an Advanced Systems Analysis and Design course perform better than students in an introductory Systems Analysis and Design course in a project assignment, given that the project assignments in these two courses are comparable in complexity and in scale.

Discussion: Descriptive statistics show that the average midterm exam grade (78\%) and final exam grade (74\%) for the Advanced SAD course are lower than the average midterm exam grade $(80 \%)$ and final exam grade $(87 \%)$ for the introductory SAD course among the multiple sessions of the same courses. However, such a comparison is meaningless because the course content including the textbook, chapter assignments, teachings, as well as the exams are quite different between the Advanced SAD and the introductory SAD courses.

Table 5. Students in an Advanced SAD Course Perform Consistently Better than Those in an Introductory SAD Course in a Project Assignment

\begin{tabular}{|l|c|c|}
\hline \multicolumn{1}{|c|}{ Project Performance } & Advanced SAD Course & Introductory SAD Course \\
\hline $\begin{array}{l}\text { Average Project Grade } \\
\text { (for both Project A and Project B) } \\
\text { (for both group and individual project assignments) }\end{array}$ & $87 \%$ & $81 \%$ \\
\hline
\end{tabular}




\begin{tabular}{|l|c|c|}
\hline $\begin{array}{l}\text { Average Project Grade } \\
\text { (for Project A only) } \\
\text { (for group project assignments only) }\end{array}$ & $87.7 \%$ & $82.7 \%$ \\
\hline $\begin{array}{l}\text { Average Project Grade } \\
\text { (for Project A only) } \\
\text { (for individual project assignments only) }\end{array}$ & $85 \%$ & $74 \%$ \\
\hline
\end{tabular}

The comparison between the student performances in these two courses should center on a teaching material and an assignment that are the same for these two courses. A non-textbook-based project assignment serves such a purpose. For the project assignments for the undergraduates, the average project grade for the Advanced SAD course was $87 \%$ whereas the average project grade for the introductory SAD course was $81 \%$, taking into accounts for both Project A and B and for both group and individual project assignments. For group project assignments of Project A only, the average project grade for the Advanced SAD course was $87.7 \%$ and that for the introductory SAD course was $82.7 \%$. For individual project assignments of Project A, the average project grade for the Advanced SAD course was $85 \%$ and that for the introductory SAD course was $74 \%$. Data (see Table 5 above) show that students in an Advanced SAD course perform consistently better than those in an introductory SAD course in a project assignment.

RQ4: Do undergraduate students in an evening class have better course performance than those in a daytime class, given that the two classes are for the same course and are conducted the same way by the same instructor?

Answer: Undergraduate students in an evening class have better course performance than those in a daytime class, given that the two classes are for the same course and are conducted the same way by the same instructor.

Discussion: Students' course performances in the two sessions-Fall 2013-C1 and Fall 2013-C2-of the undergraduate SAD course are comparable because these two sessions were taught exactly with the same content, at the same pace, by the same instructor, during the same semester, and even on the same days. Since the instructor has taught the SAD course in a previous semester prior to Fall 2013, the instructor was not using the teaching in the afternoon sessions as rehearsals for that of the evening sessions - the instructor conducted the two sessions in the same manner and specifically ensured the same pace with the same content on the same day.

Data show that students in the evening session (C2) have an average project grade of $85 \%$, midterm exam grade of $76 \%$, and final exam grade of $86 \%$ whereas those in the afternoon session $(\mathrm{C} 1)$ have an average project grade of $76 \%$, midterm exam grade of $70 \%$, and final exam grade of $82 \%$ (see Table 6 below). The project completion rates and course retention rates for the two sessions were all $100 \%$. Undergraduate students in the evening class perform consistently better in all of the three assessment dimensions than those in the afternoon class. The reason may be due to the fact that students in the evening classes typically have daytime jobs. Some of them work in information technology related areas, experiences from which can help with the class performance. In comparison, students in the afternoon classes are mostly full-time students or those who have work-study jobs on campus and these workstudy jobs are mostly not technology related. For these two sessions, the undergraduate students in the evening class seemed to be more mature that those in the afternoon class. For instance, they paid more attention to the teachings and were more eager to learn and think independently.

Table 6. Students in the Evening Session of an Undergraduate SAD Course Perform Consistently Better than those in the Afternoon Session of an Undergraduate SAD Course

\begin{tabular}{|l|c|c|}
\hline \multicolumn{1}{|c|}{ Course Performance } & $\begin{array}{c}\text { Undergraduate SAD Course } \\
\text { Evening Session }\end{array}$ & $\begin{array}{c}\text { Undergraduate SAD Course } \\
\text { Afternoon Session }\end{array}$ \\
\hline Average Project Grade & $85 \%$ & $76 \%$ \\
\hline Average Midterm Exam Grade & $76 \%$ & $70 \%$ \\
\hline Average Final Exam Grade & $86 \%$ & $82 \%$ \\
\hline Project Completion Rate & $100 \%$ & $100 \%$ \\
\hline Course Retention Rate & $100 \%$ & $100 \%$ \\
\hline
\end{tabular}

RQ5: Do graduate students perform better than undergraduate students for the same course taught in the same manner? 
Answer: Graduate students perform better than undergraduate students for the same course taught in the same manner.

Discussion: The online, eight-week Object-oriented SAD course for the graduate students in Fall 2014 semester has the same course content and is taught by the same instructor in the same mode as the online, eight-week Advanced SAD course for the undergraduate students in Fall 2013. Neither of the two courses has a project assignment. The average final exam grade for the graduate students was $80 \%$ whereas the average final exam grade for the undergraduate students was only $73 \%$ (see Table 7 below).

Table 7. Graduate Students Perform Better than Undergraduate Students for the Same Advanced SAD Course Taught in the Same Manner

\begin{tabular}{|c|c|c|}
\hline Course Performance & $\begin{array}{c}\text { Graduate Advanced } \\
\text { SAD Course }\end{array}$ & $\begin{array}{c}\text { Undergraduate Advanced } \\
\text { SAD Course }\end{array}$ \\
\hline Average Final Exam Grade & $80 \%$ & $73 \%$ \\
\hline
\end{tabular}

Even though the undergraduate students in the Advanced SAD course have been exposed to an introductory SAD course as a prerequisite and there was no prerequisite for the graduate OO-SAD course, the performance from the graduate students is better than that of the undergraduate students. This may be due to graduate students' increased critical thinking capacities, increased organization/time management skills, more course content-related work experiences, and better self-discipline for an online course when comparing with their undergraduate counterparts.

\section{CONCLUSIONS}

The aim of a project-based systems course is to allow information systems students have good learning outcomes. Good learning outcomes can be collectively assessed by students' average project grade, midterm/final exam grades, as well as the project completion rate and course retention rate, etc. Student data of these assessments collected from the four sessions of an introductory systems analysis and design course and the six sessions of an advanced systems course show that: (1) A group project assignment has a higher project completion rate and better project performance than those of an individual project assignment; )2) Groups with a group size of two have a higher project completion rate and better group project performance than those of a larger group size such as four; (3) Students in an advanced systems course consistently perform better than those in an introductory systems course for a project assignment; (4) Undergraduate students in an evening class have better course performance than those in an afternoon class, given that the two classes are conducted in the same manner; and (5) Graduate students perform better than undergraduate students for the same course taught in the same manner.

The above conclusions were based on the descriptive statistics of the multiple sessions of the introductory and advanced systems courses. Only the statistics of the averages were considered in this paper. Future research would look further into the statistics of the variances and gain more insights from inferential statistics.

There are many more nuances in effectively teaching systems courses with hands-on, real-world projects besides what have been discussed in this paper. The author would also further examine and discuss these nuances in future research.

For instance, it is important to include more online courses in the research. The author has only experimented with the individual project assignments in two online sessions in earlier semesters and neither the project completion rate nor the project average grade was as good as those in on-ground courses with group project assignments. The author taught two online eight-week courses later but did not introduce real-world projects because of the relatively low performance data from the previous online courses. It is important to determine if introducing hands-on, real-world projects is feasible and effective in online courses especially those with short durations (e.g., eight weeks only). The low performance data may be due to the individual rather than the group project assignment, or the difficulty of conveying the complexity of hands-on real-world projects via the online format. Additional complexity of the project comes from the interconnections among the groups because each group works on a subsidiary website and all the subsidiaries interconnect under a coherent overall governance of the organization's main website. Such a complexity was introduced and discussed in on-ground courses and intra-group interactions were encouraged throughout the semester to address the interconnections. But how can such a complexity be enacted in an online 
educational environment where both within-group and intra-group interactions are needed? The author intends to further experiment with group project assignment in online courses and study how to best convey and handle the complexity of hands-on, real-world projects within an online learning management system such as Blackboard.

Even for on-ground courses, there are many areas that need further investigation and improvement as well. For instance, students may have different cultures and backgrounds. Some students are of international origins. International students tend to have lesser work experiences due to the limitations of their student visa; hence, they have lesser business background on systems and lesser coding experiences on real-world projects. Their communication skills are often lacking as well. Since the author was an international student before and serves on the university committee for international students and scholars, special attention was paid to cultural diversity and harmony when helping to form the groups. Both group compositions with international students only and with both international and domestic students were formed voluntarily and with the help of the instructor. There were no problems or complaints. Future research will experiment with the various group compositions with the international students and study how to effectively address their unique needs and at the same time not to adversely affect the domestic students in their learning but allow them to grow more understandings of diversity.

Another research area is to experiment with the students' comfort zones and encourage them to think "outside of the box." A student who has already had some leadership skills may feel comfortable when volunteering to be a group leader. Should every student be exposed to the leadership training in a systems course because every graduate from a CIS degree program should have an ability to demonstrate sufficient background in information systems planning and project management as required by ABET? Does such ability imply leadership as well? Maybe students should rotate their roles in a group project assignment and every student should become the group leader for a period of time. It is the educators' responsibilities to provide opportunities for students to experience and be able to become more comfortable when outside their comfort zones.

\section{REFERENCES}

1. Kovacs, P. J., Scarpino, J. J., \& Wang, W. (2013). A framework for an interactive web-based application course, Issues in Information System, 14(1), 300-306

2. Satzinger, J. W., Jackson, R. B., \& Burd, S. D., (2011). Systems Analysis and Design in a Changing World, 6th Edition, Course Technology Publisher.

3. Shelly, G. B., \& Rosenblatt, H. J. (2011). Systems Analysis and Design, Ninth Edition. Cengage Learning Publisher.

4. Wang, W. (2015). Building a contemplative IS workforce through promoting mindfulness in IS design—a case study. Proceedings of the $18^{\text {th }}$ Americas Conference on Information Systems, San Juan, Puerto Rico, USA, August 2015.

5. Wang, W. (2015). Empower patients, enhance care. Proceedings of the $25^{\text {th }}$ International Conference of Pacific Rim Management. Los Angeles, CA. July 2015.

\section{APPENDIX}

\section{Proposal Template}

As given in this proposal template, the proposal should have the following sections and headings. Section length is recommended and can be flexible.

\section{Title Page}

Title of project in initial capital letters (e.g., Response to Request for Proposal “...”)

Presented by: name and contact information

Date

An appropriate picture of the product, a team logo, or both (if there is any) 


\section{Table of Contents}

\section{Executive Summary (0.5 page)}

Provide a brief summary of the proposal, highlighting the proposed technical and management approach.

\section{Systems Request Summary (0.5 page)}

Describe the basis of the systems request.

Findings of Preliminary Investigation (0.5-1 page)

Describe the findings of preliminary investigation, including a SWOT analysis and a description of the project's scope, constraints, and feasibility.

\section{Systems Requirements (2 pages)}

Build the system's logical model corresponding to the chosen development method. For instance, if you group has chosen OO development method, then please include the following: 1) Draw an activity diagram showing sample workflows; 2) Identify subsystems and draw a sample use case diagram; 3) Draw a sample domain model class diagram for one subsystem; 4) Develop a sample use case description in a table; 5) Draw a sample system sequence diagram; and 6) Draw a sample state machine. Recommend a development strategy, e.g., customize a software package (Drupal, Moodle, etc.) or develop in-house, etc.

\section{Systems Design Specifications (2-3 pages)}

Create the system's physical model: 1) Draw the system's architecture; 2) Provide sample design of the system, include sample user interface, outputs, inputs, files, databases, and network specifications; 3) Draw ERDs showing all major entities and their relationships, and create a sample normalized table design that includes all necessary fields and appropriate keys. Briefly describe system environment such as constraints or conditions affecting the system, such as compatibility requirements, transaction volumes requirements, data storage requirements, online response time, processing schedules, reporting deadlines, backup and recovery requirements, etc.

\section{Systems Implementation (0.5 page)}

Recommend implementation strategies and testing plans.

\section{Systems Support and Security $(0.5$ page $)$}

Recommend systems support strategies. Describe systems security concerns and solutions. Describe strategy for systems scalability.

\section{Time/Cost Estimates and Project Management (1-2 pages)}

Describe how the entire project will be managed, including a detailed timetable with milestones (as the above analysis in different sections is still preliminary or exemplary). Draw Gantt chart if possible. Provide detailed schedules, major milestones, cost estimates, and staff requirements for the entire system development life cycle. Divide up into major steps and major categories. Propose a team and divide responsibilities and duties among team members.

\section{Expected Benefits (0.5 page)}

Describe the anticipated tangible and intangible benefits and a timetable that shows when they are to occur. 


\section{Project Lead Qualification ( 0.5 page)}

Describe the qualification of the project lead and highlight any specific experience or expertise that is relevant to the project.

Appendix (if there is any supporting information) 